\title{
No association between the presence of periodontal disease and poor IVF outcomes: a pilot study
}

This article was published in the following Dove Press journal: International Journal of Women's Health

\author{
Dalia Khalife' \\ Ali Khalil \\ Mohamad N Itani ${ }^{2}$ \\ Fatin Khalifeh' \\ Sara Faour' \\ Anastasia Salame' \\ Ghina Ghazeeri' \\ 'Department of Obstetrics \& \\ Gynecology, American University of \\ Beirut Medical Center, Beirut, Lebanon \\ ${ }^{2}$ Department of Dentistry, American \\ University of Beirut Medical Center, \\ Beirut, Lebanon
}

Background: Periodontal disease can lead to bacteremia with release of cytokines, affecting implantation in women trying to conceive through in vitro fertilization (IVF). A potential association between maternal periodontal disease and poor IVF outcomes has been described.

Objective: The aim of the study is to assess whether pre-existing periodontal disease has any effect on IVF parameters.

Method: A pilot study composed of 34 women was conducted at a tertiary care center. Prior to IVF, dental examination, IVF parameters were collected.

Results: Thirty-four women participated in the study. The outcomes of 28 women $(82.3 \%)$ were analyzed. Out of the 28 patients, 17 patients had a positive pregnancy test $(60.7 \%)$ with a total of 13 live births (46.4\%) and 4 pregnancy losses (14.3\%). Plaque and bleeding index scores were both lower in patients who achieved pregnancy after IVF yet did not reach statistical significance $(p=0.309$ and 0.422 ). Comparison of mean values for the different infertility parameters showed no significant differences among women with different IVF outcomes $(p>0.05)$. Different degrees of inflammation of the gingiva did not have an effect on the different clinical parameters and the live birth rates.

Conclusion: The evidence provided by the present study does not support the hypothesis. Addressing the status of oral health before any infertility treatment remains to be elucidated. Keywords: periodontal disease, in vitro fertilization, infertility, inflammation, live birth

\section{Plain language summary}

Periodontal disease is the presence of inflammation at the level of periodontium. Our hypothesis was based on the fact that the presence of the oral bacteria may have an impact on the implantation of embryos in women trying to conceive through IVF. Our present study aimed to find any association between the presence of periodontitis and poor IVF outcomes.

Thirty-four women were recruited. A dental examination was performed before undergoing any ovarian stimulation. IVF parameters were then collected, and pregnancy outcomes were recorded. Outcomes of 28 women were analyzed. The live birth rate was $46.4 \%$ and miscarriage rate was $14.3 \%$. the different infertility parameters were not different between the cohort. The presence of different degree of inflammation of the gingiva did not have an effect on the clinical parameters. No correlation was found between poor dental status and poor IVF outcomes. Assessing dental hygiene and status before undergoing any IVF treatment remains to be elucidated.
Correspondence: Ghina Ghazeeri Department of Obstetrics \& Gynecology, American University of Beirut Medical Center, PO BOX: II3-6044, Beirut, Lebanon

Tel +96| 1350000

Extension 5618

Email gg02@aub.edu.lb 


\section{Introduction}

Periodontal disease (PD) is a common chronic infectious disorder with a prevalence reaching $45.9 \%$ in the United States. ${ }^{1}$ It is the result of a complex interaction between the presence of bacteria and risk factors such as smoking, uncontrolled diabetes, and genetic predisposition. It refers to the inflammation of soft tissues around the teeth with progressive destruction of the alveolar bone and the periodontal ligament, leading to periodontal pocket formation and/or gingival recession. ${ }^{2}$ The presence of anaerobic and gram-negative pathogens in dental plaques is the main reason for disease manifestation with persistent inflammation and destruction of supporting tissues. ${ }^{3}$

Poor oral health has been associated with multiple systemic disorders, including type 2 diabetes, cardiovascular, and kidney diseases. ${ }^{2,4-6}$ It has been appraised that maternal periodontitis is associated with an increased risk of adverse pregnancy outcomes such as premature birth, low birth weight, preeclampsia, perinatal mortality, and increased time to conception. ${ }^{7-11}$ Despite significant advancements in assisted reproductive technologies, implantation failure remains frequent and devastating. Periodontal health status of infertile patients has been given importance and linked to delayed conception, infertility, and poor in vitro fertilization (IVF) outcomes. Since treating oral conditions with good oral hygiene and dental care is easy, some investigators have speculated that improvements in oral health before starting any ovarian stimulation cycle may prevent the occurrence of adverse IVF outcome, ${ }^{12,13}$ while others have considered it as a modifiable risk factor for failed implantation. ${ }^{11}$

We hypothesize that PD creates an adverse environment leading to a reduced rate of conception following IVF. In view of the limited research data available on the link between maternal PD and the effectiveness of fertility treatment in achieving a pregnancy, the objective of this study is to assess whether pre-existing PD has any effect on IVF parameter outcomes, including the number of oocytes retrieved, number of mature oocytes (MII), number of transferred embryos, as well as on pregnancy outcome defined as live births.

\section{Materials and methods}

\section{Study design, subjects, and recruitment}

In this prospective pilot study, 34 infertile women, who attended the private and outpatient clinics of Obstetrics and Gynecology department at the American University of Beirut
Medical Center (AUBMC) were included in the study at the start of their first controlled ovarian stimulation cycles for IVF. Of the 90 women who were approached, only 34 women (37.8\%) accepted to be enrolled in the study from June 2016 to June 2017. Women included had a normal uterine cavity (assessed by hysteroscopy or hysterosalpingography), with a normal hormonal profile, and at least 20 natural teeth. Women with endometriosis, history of inflammatory or chronic infectious disease, inherited or acquired thrombophilia, and severe male infertility (azoospermia) were excluded.

At their first visit, women were interviewed about their socio-economic and educational status, the frequency of tooth brushing and flossing. Following dental examination, women underwent their IVF cycle, using the antagonist or the agonist protocol combined with human menopausal gonadotropin. Embryology characteristics of the cycles along with pregnancy outcomes were recorded. Clinical data were collected at the second/third day of the period, before starting controlled hormonal stimulation. Blood sample C-reactive protein (CRP) level was determined prior to initiating their IVF cycle. In addition, women underwent a baseline dental examination at the dentistry department of the AUBMC. Plaque indexes and bleeding indexes were examined and recorded. Pregnancy rate is defined as the presence of a positive hCG test. Live birth rate is defined as an ongoing pregnancy after 24 weeks of gestation.

\section{Clinical examination}

Calibration of examiners was completed prior to the start of the study. A clinical record of previous dental and periodontal treatment information was collected, including time and type of treatment received. Clinical measures of periodontal health were collected from all subjects including probing depth of sulcus, using a PUNC-15 probe to measure the sulcus depth for all six sites of each tooth in the oral cavity from the gingival margin to the periodontal attachment.

Plaque index was measured according to Silnus and Loeref with the following grading: 0 for teeth showing no staining to the disclosing, 1 for teeth with one-third of stain on the clinical crown, 2 when three-quarters of the clinical crown was stained, and 4 for teeth that showed greater than three-quarters of staining. Bleeding index was recorded as 0 when no bleeding and inflammation were detected, 1 when no bleeding and mild inflammation were 
observed, 2 for bleeding on probing/pressure with moderate inflammation, and 3 for spontaneous bleeding and severe inflammation.

Periodontal disease was classified according to the American Academy of Periodontology. ${ }^{14}$ Women were classified as having gingivitis if no pocketing $(\leq 3 \mathrm{~mm})$ and no bleeding on probing were observed; chronic periodontitis was defined as pockets $(\geq 4 \mathrm{~mm})$ in two or more sites and bleeding on probing. No dental radiographs were taken.

\section{Statistical analysis}

Results were presented for 34 participants. For all included women, descriptive and comparative statistics of demographics were analyzed between pregnant and nonpregnant women. Chi-square test was used to compare percentages for categorical variables concerning outcomes related to IVF treatment. Student's $t$ test or one-way analysis of variance was used to compare mean \pm standard deviation (SD) for continuous variables.

Statistical analysis was performed using SPSS IBM version 25 software, and a value of $p<0.05$ was considered to be statistically significant.

\section{Ethical approval}

The study was approved by the Institutional Review Board committee (Protocol Number: OGY.GG.13) at the AUBMC with compliance with the Declaration of Helsinki. Written informed consent was obtained from each participant.

\section{Results}

A total of 34 women undergoing controlled ovarian stimulation with IVF treatment participated in the study. Six patients were lost to follow-up, and the outcomes of 28 women $(82.3 \%)$ were analyzed. The participants were between 22 and 37 years. Patients were assessed for evidence of PD. None of the women included satisfied the diagnosis of periodontitis. All women had different degrees of gingivitis, which were divided into mild (47.1\%), moderate $(8.8 \%)$, and severe $(23.5 \%)$. Out of the 28 patients, 17 patients had a positive pregnancy test (60.7\%) with a total of 13 live births (46.4\%) and 4 pregnancy losses (14.3\%) (see Figure 1). Unexpectedly, nine were twins' pregnancies (69.2\%). Fifty-six percent of the women recruited were unemployed with a monthly income of less than 1000\$ (see Table 1). In general, our

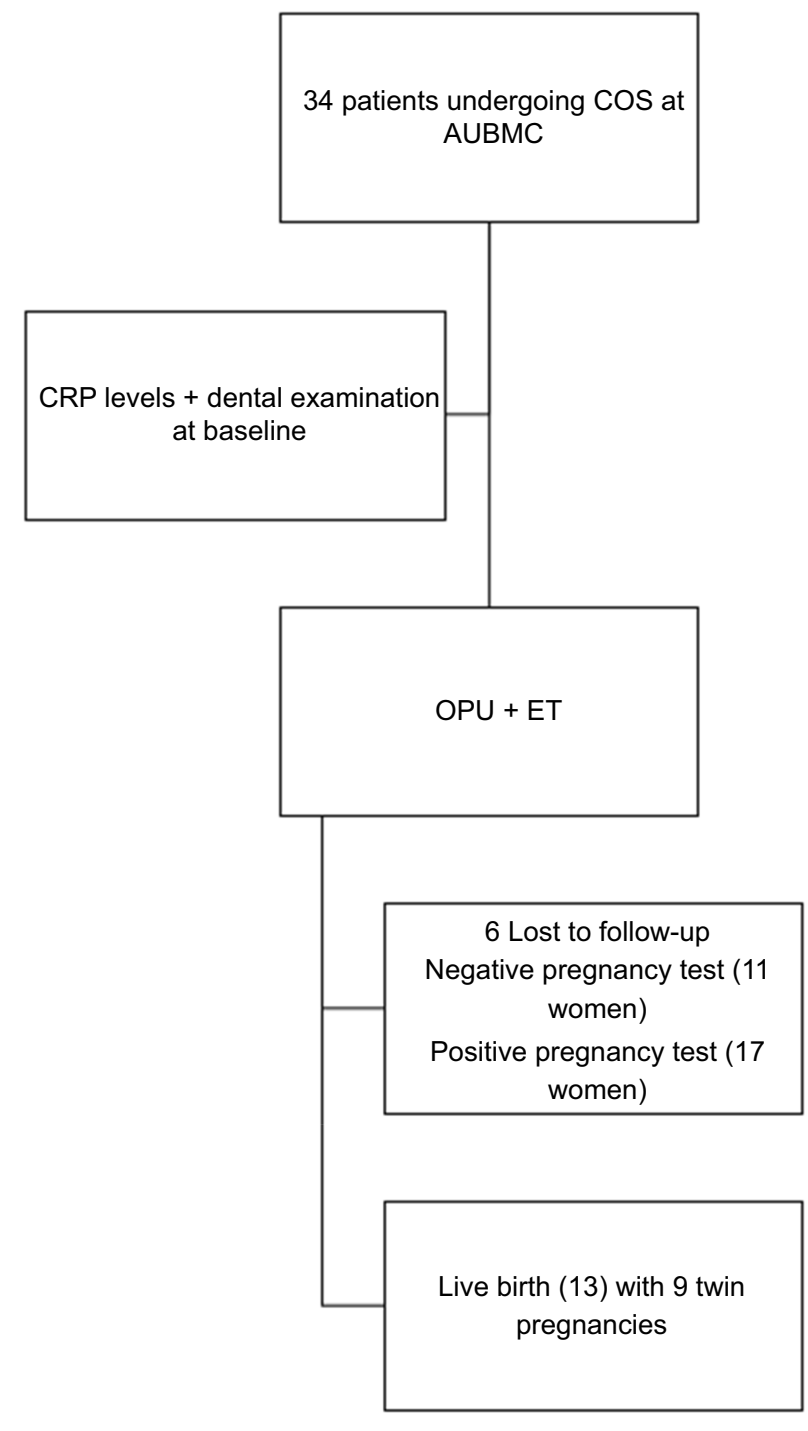

Figure I Flow chart of patients.

Abbreviations: COS, controlled ovarian stimulation; AUBMC, American University of Beirut Medical Center; CRP, C-reactive protein; OPU, Ovum Pick up; ET, Embryo transfer.

patients were of poor socioeconomic profile; only $39.1 \%$ reported regular flossing and $17.6 \%$ regularly used gargle.

The following parameters were examined in all participants: number of oocytes retrieved, number of matured (MII) oocytes, number of fertilized oocytes, and the number of embryos transferred. All women were comparable at baseline (see Tables 1 and 2). The mean duration of infertility was 5 years. Women who had a positive pregnancy test were more likely to be young, with a lower BMI and a higher number of oocytes retrieved. However, these differences did not reach statistical significance $(p>0.05)$. Ironically, CRP levels were slightly higher in patients with positive outcomes; however, it did not reach statistical significance $(4.2 \pm 3.5$ versus $5.6 \pm 6.5, p=0.469)$. 
Table I Baseline characteristics at the time of controlled ovarian stimulation of all women (categorical variables)

\begin{tabular}{|c|c|c|c|c|}
\hline & & Not pregnant $(n=I \mid)$ & $\begin{array}{l}\text { Pregnant } \\
(n=\mid 7)\end{array}$ & $P$-value \\
\hline Diagnosis of periodontal disease & $\begin{array}{l}\text { Mild gingivitis } \\
\text { Moderate gingivitis } \\
\text { Severe gingivitis }\end{array}$ & $\begin{array}{l}6(60) \\
1(10) \\
3(30)\end{array}$ & $\begin{array}{l}9(64.3) \\
1(7.1) \\
4(28.6)\end{array}$ & 0.962 \\
\hline Infertility cause & $\begin{array}{l}\text { Unexplained } \\
\text { Female infertility } \\
\text { Male infertility } \\
\text { Combined infertility }\end{array}$ & $\begin{array}{l}2(18.2) \\
4(36.4) \\
3(27.3) \\
2(18.2)\end{array}$ & $\begin{array}{l}3(17.6) \\
4(23.5) \\
6(35.3) \\
4(23.5)\end{array}$ & 0.894 \\
\hline Infertility type & $\begin{array}{l}\text { Primary infertility } \\
\text { Secondary infertility }\end{array}$ & $\begin{array}{l}10(90.9) \\
1(9.1)\end{array}$ & $\begin{array}{l}14(82.4) \\
3(17.6)\end{array}$ & 0.639 \\
\hline Education & $\begin{array}{l}\text { School } \\
\text { University } \\
\text { Higher education }\end{array}$ & $\begin{array}{l}9(8 \mathrm{I} .8) \\
1(9.1) \\
1(9.1)\end{array}$ & $\begin{array}{l}12(70.6) \\
3(17.6) \\
2(11.8)\end{array}$ & 0.779 \\
\hline $\begin{array}{l}\text { Employment status } \\
\text { Household income }\end{array}$ & $\begin{array}{l}\text { Unemployed } \\
\text { Less than } 1000 \$ \\
\text { Between } 1000 \text { and } 2000 \$ \\
\text { More than } 2000 \$\end{array}$ & $\begin{array}{l}6(54.5) \\
8(72.7) \\
3(27.3) \\
0(0)\end{array}$ & $\begin{array}{l}\text { I4 (82.4) } \\
\text { II (64.7) } \\
4(23.5) \\
2(11.8)\end{array}$ & $\begin{array}{l}0.259 \\
0.498\end{array}$ \\
\hline $\begin{array}{l}\text { Smoking status } \\
\text { Oral hygiene }\end{array}$ & $\begin{array}{l}\text { Smoker } \\
\text { Use of floss } \\
\text { Use of gargle }\end{array}$ & $\begin{array}{l}7(63.6) \\
3(27.3) \\
0(0)\end{array}$ & $\begin{array}{l}9(52.9) \\
2(11.8) \\
3(17.6)\end{array}$ & $\begin{array}{l}0.576 \\
0.567 \\
0.679\end{array}$ \\
\hline
\end{tabular}

Table 2 Baseline characteristics and IVF parameters evaluated at the time of controlled ovarian stimulation of all women (continuous variables)

\begin{tabular}{|l|l|l|l|}
\hline Parameters & $\begin{array}{l}\text { Not preg- } \\
\text { nant }(\mathbf{n}=\mathbf{I} \text { I) }\end{array}$ & $\begin{array}{l}\text { Pregnant } \\
(\mathbf{n}=\mathbf{I} \text { ) })\end{array}$ & P-value \\
\hline $\begin{array}{l}\text { Age (years) } \\
\text { BMI }\left(\mathrm{kg} / \mathrm{m}^{2}\right)\end{array}$ & $30 \pm 4$ & $27 \pm 5$ & 0.621 \\
$\begin{array}{l}\text { Duration of infertility } \\
\text { (years) }\end{array}$ & $5 \pm .02 \pm 4.2$ & $27.1 \pm 6.2$ & 0.358 \\
$\begin{array}{l}\text { Numbers of oocytes } \\
\text { retrieved }\end{array}$ & $7.3 \pm 6.4$ & $5 \pm 4$ & 0.434 \\
$\begin{array}{l}\text { Number of MII } \\
\text { oocytes }\end{array}$ & $5.6 \pm 4.4$ & $14.6 \pm 9.4$ & 0.446 \\
$\begin{array}{l}\text { Number of fertilized } \\
\text { oocytes }\end{array}$ & $5 \pm 4.3$ & $10.2 \pm 8.9$ & 0.338 \\
$\begin{array}{l}\text { Number of trans- } \\
\text { ferred embryos } \\
\text { C-reactive protein }\end{array}$ & $2.4 \pm 1.9$ & $2.8 \pm 0.7$ & 0.276 \\
\hline
\end{tabular}

Plaque indexes and bleeding indexes score were not significantly lower in patients who achieved pregnancy after IVF treatment ( $p=0.309$ and 0.422 , respectively) (see Table 3).
Table 3 Mean values and standard deviations (SD) of plaque and bleeding indexes prior to IVF treatment among all women

\begin{tabular}{|c|c|c|c|}
\hline & $\begin{array}{l}\text { Not pregnant } \\
(n=\mid I)\end{array}$ & $\begin{array}{l}\text { Pregnant } \\
(n=17)\end{array}$ & $P$-value \\
\hline $\begin{array}{l}\text { Plaque } \\
\text { index }\end{array}$ & $2.63 \pm 0.38$ & $2.2 \pm 0.76$ & 0.309 \\
\hline $\begin{array}{l}\text { Bleeding } \\
\text { index }\end{array}$ & $1.67 \pm 0.68$ & $1.49 \pm 0.63$ & 0.422 \\
\hline
\end{tabular}

Finally, periodontal status was divided into three groups: mild, moderate, and severe gingivitis. Comparison of mean values for the different infertility parameters showed no significant differences among women with different IVF outcomes $(p>0.05)$. Similarly, statistically significant differences were not observed in women according to their periodontal status in relation to their mean values of plaque and bleeding indexes (see Table 4).

Furthermore, the overall success of IVF treatment reported as a live birth was also examined in the three groups. Different degrees of inflammation of the gingiva 
Table 4 IVF outcomes stratified by the different degrees of gingivitis

\begin{tabular}{|c|c|c|c|c|c|c|c|}
\hline & \multicolumn{2}{|c|}{ Mild gingivitis } & \multicolumn{2}{|c|}{ Moderate gingivitis } & \multicolumn{2}{|c|}{ Severe gingivitis } & \multirow[t]{2}{*}{$P$-value } \\
\hline & $\begin{array}{l}\text { Not preg- } \\
\text { nant } \\
(n=7)\end{array}$ & $\begin{array}{l}\text { Live } \\
\text { birth } \\
(n=8)\end{array}$ & $\begin{array}{l}\text { Not preg- } \\
\text { nant } \\
(n=I)\end{array}$ & $\begin{array}{l}\text { Live } \\
\text { birth } \\
(n=I)\end{array}$ & $\begin{array}{l}\text { Not preg- } \\
\text { nant } \\
(n=3)\end{array}$ & $\begin{array}{l}\text { Live } \\
\text { birth } \\
(n=4)\end{array}$ & \\
\hline Age (years) & $30 \pm 5$ & $25 \pm 4$ & $30 \pm 4$ & $27 \pm 5$ & $29 \pm 4$ & $27 \pm 2$ & 0.305 \\
\hline BMI $\left(\mathbf{k g} / \mathbf{m}^{2}\right)$ & $28.34 \pm 4.83$ & $27.67 \pm 6.71$ & $30.06 \pm 4.56$ & $28.9 \pm 6.45$ & $30.27 \pm 4.96$ & $24.94 \pm 6.5$ & 0.655 \\
\hline Number of oocytes retrieved & $7 \pm 9.9$ & $\begin{array}{l}14.33 \\
\pm 12.34\end{array}$ & $5 \pm 6.7$ & $5 \pm 6.7$ & $9 \pm 7.94$ & $|4.5 \pm 0.7|$ & 0.240 \\
\hline Number of MII oocytes & $4.5 \pm 6.36$ & $\begin{array}{l}13.33 \\
\pm 11.68\end{array}$ & $5 \pm 6.7$ & $5 \pm 6.7$ & $6.67 \pm 5.86$ & $10.5 \pm 3.54$ & 0.168 \\
\hline Number of fertilized oocytes & $4.5 \pm 6.36$ & $8.67 \pm 4.93$ & $4 \pm 3.99$ & $5 \pm 6.7$ & $6.33 \pm 5.51$ & $9.5 \pm 0.71$ & 0.200 \\
\hline $\begin{array}{l}\text { Number of transferred } \\
\text { embryos }\end{array}$ & $2 \pm 2.83$ & $2.67 \pm 0.58$ & $3 \pm 2.78$ & $3 \pm 2.78$ & $2.67 \pm 2.52$ & $2.5 \pm 0.71$ & 0.835 \\
\hline C-reactive protein & $4.48 \pm 4.49$ & $8.02 \pm 7.22$ & $7.6 \pm 6.8$ & $0.7 \pm 0.44$ & $3.2 \pm 1.18$ & $0.67 \pm 0.47$ & 0.464 \\
\hline Plaque index & $2.69 \pm 0.4$ & $2.33 \pm 0.75$ & $2.33 \pm 0.56$ & $\mathrm{I} .8 \mathrm{I} \pm 0.67$ & $2.61 \pm 0.42$ & $2.01 \pm 0.92$ & 0.120 \\
\hline Bleeding index & $1.58 \pm 0.79$ & $1.35 \pm 0.58$ & $\mathrm{I} \pm 0.79$ & $2.66 \pm 0.89$ & $1.48 \pm 0.28$ & $2.14 \pm 0.4$ & 0.121 \\
\hline Duration of infertility (years) & $6 \pm 3$ & $5 \pm 2$ & NA & $1.8 I \pm 0.67$ & $4 \pm 1$ & $3 \pm 3$ & 0.297 \\
\hline
\end{tabular}

Abbreviation: NA, Not available.

did not have an effect on any of the different clinical parameters of the IVF as well as on live birth rates (see Table 4).

\section{Discussion}

This pilot study investigating the possible link of PD to poor IVF outcomes suggests no association between the presence of PD and the possibility of conception after IVF. Apparently, periodontal disease has no effect on implantation since $69 \%$ of the live birth were twin pregnancies. We believe that this is the first study defying any effect of PD on implantation, reinforcing the results of a recent metaanalyses on pregnant patients. This meta-analysis included 11 trials where only half of these trials were of high methodological quality. It showed no effect of treating PD on the overall pregnancy outcomes. ${ }^{15}$

Despite major improvements in assisted reproductive technologies, implantation failure remains among the most confusing and devastating outcome encountered. Several etiologies have been suggested, one of which is the presence of a possible infection responsible for the negative effect on endometrial receptivity. PD was the main objective in our study. Studies in the literature showed that the presence of inflammation and infection at the level of periodontium induces the release of inflammatory markers into the bloodstream affecting implantation, adhesion, and embryo invasion. ${ }^{16}$ In addition, a vaginal infection is well linked to an increased level of inflammatory cytokines and thus a poorer reproductive outcome due to the effect on embryo development. ${ }^{17}$ Therefore, it was suggested that a chronic infection at the level of the oral cavity might also affect the success of implantation of the embryo. However, we failed to show that women with poor oral health had any effect on the reproductive outcomes, and the implantation process was not affected by the presence of a chronic infection. This observation may put under question the whole hypothesis about any infection leading to bacteremia that affects the reproductive outcomes.

The effect of PD on poor IVF outcomes is well documented in the literature, especially in patients receiving ovulation induction treatment. ${ }^{12}$ It is believed that an abnormal dialogue exists between the embryo and the endometrium in women with difficulties in conceiving. A large body of evidence suggests that chronic endometritis is a contributing factor to implantation failure. ${ }^{18,19}$ Longstanding inflammatory processes such as periodontitis may lead to the release of inflammatory markers such as endotoxins and cytokines into the bloodstream. These cytokines activate the maternal inflammatory response with an increase in the level of prostaglandin reaching the uterine cavity, hence, lowering the chance of embryo implantation. This might play a role in the pathophysiological process of endometrial infection and subsequent IVF failure. ${ }^{7,11,20-22}$ Our particular interest in this study was the possible link between poor oral health to IVF outcomes, thus investigating the effect of periodontitis on 
the ovarian response and the endometrium. However, we found that the presence of bacteria in the periodontium did not have an effect on the outcome of infertility treatments.

Interestingly, Hart and colleagues found a negative effect of PD on the time taken to conceive; thus, women with periodontitis needed two additional months to achieve a pregnancy. This observation was limited to nonCaucasian women (Asians). It highlighted the immunological differences seen among different ethnicities. ${ }^{11}$ Therefore, the lack of association found in our study can be explained by the different ethnicities of our population. Surprisingly, some patients never had dental examination or ever used a toothbrush, yet their probing depth and clinical presentation did not reveal an expected fullblown periodontitis. The variation in clinical response among different individuals is related to differences in mounting an immune response to infection because of the genetic diversity. ${ }^{23}$ Thus, certain ethnic populations generate a balanced systemic inflammatory response preventing tissue damage and adverse effect on various organs and structures, such as the uterine cavity. This can also explain the ethnic disparity in the success of fertility treatments reported in two other studies ${ }^{24,25}$ Our findings suggest that either PD has no effect on having poorer IVF outcomes or that our population has some kind of genetic predisposition enabling the clearance of infection without affecting the outcome of conception.

The oral cavity presents its own microbiome. More than 200 bacterial species are found in periodontal pockets, including Porphyromonas gingivalis and Prevotella intermedia. Inflammation, mediated by bacterial lipopolysaccharide results in endotoxemia, increasing the risk of unsuccessful conception. 22,26,27 However, it is not well established whether the composition of this bacterial load in the upper oral cavity is subject to genetic susceptibility. The results reported in our study should be interpreted with caution. Another important issue to highlight is the Mediterranean diet. Middle Eastern foods emphasize on whole grains, healthy fats like olive oil and fish, cheese, yogurts, lean proteins, fruits, and veggies yielding a wide variety of vitamins and minerals. This particular diet may help in clearing the infection or decreasing the bacterial load in bloodstream and thus minimizing its effect on the uterine cavity. ${ }^{28}$

The results of our study were not in line with previous studies that showed that preexisting periodontal inflammation is negatively correlated to the IVF parameters as measured by the number of follicles and embryos transferred. ${ }^{12,13}$ Other studies have found that ovulation induction worsens the inflammation of the gingiva, due to the presence of estrogen and progesterone receptors on human gingiva through an alteration in the vascular system of the gingiva. ${ }^{12,29,30}$ Although we did not examine our patients after hormonal stimulation, the results of these studies are put into question in view of the high live birth rate in our study.

\section{Strengths and weaknesses}

To our knowledge, this is the first study in the Middle East to investigate the possible effect of a pre-existing PD on the outcome of IVF, and therefore a potential need for a dental checkup prior to IVF. We showed that preexisting gingivitis had no effect on the outcomes of IVF with respect to number of oocytes retrieved, MII oocytes and embryos transferred. In addition, it had no effect on the live birth rate.

Despite that our study was carried out in an economically disadvantaged population, where patients had very poor educational and demographic characteristics, the socio-economic status and low access to dental care did not have an effect on conception and did not bias our results (live birth rate of $46.4 \%$ ). Another strength of this study is the exclusion of women with endometriosis which is linked to the presence of endometrial pathogens, affecting endometrial receptivity. ${ }^{31}$ Kavoussi, in 2009, has explained the link between endometriosis and PD through a dysregulation in the global immune system. By excluding this subpopulation at the initial recruitment, selection bias was therefore eliminated from our results. ${ }^{32}$

However, our study has several limitations. The number of patients involved is too small to offer a great significance of the result obtained. Yet, only $37.8 \%$ of the patients approached agreed to consent and be part of the study. Furthermore, studies have previously shown that controlled ovarian stimulation has a detrimental effect on existing PD. ${ }^{12,13,33}$ We failed to examine the effect of hormones on preexisting periodontal infection due to technical problems.

To date, few studies have been published reporting on the effect of PD on IVF outcomes. These studies are conducted on small population samples, thus the need for further research to confirm the direct effect of this chronic bacterial condition on IVF outcomes.

\section{Conclusion}

An emerging cause of implantation failure has been attributed to endometrial infection. ${ }^{34,35}$ Whether endometrial 
microbiome is related to colonization from the vaginal compartment or whether it is related to colonization of bacteria from other sites such as the oral cavity is yet to be proven in order to establish clinical management.

The evidence provided by the present study does not support the hypothesis that PD is associated with poor IVF outcomes. Studies in this field are still scarce and therefore additional randomized studies are needed to reach a conclusive evidence. Such studies should focus on the effect of controlled ovarian stimulation on the preexisting PD. Nevertheless, any beneficial effect of the treatment on this condition is yet to be defined.

As many medical conditions are related to a poor oral health, women are encouraged to seek dental care in order to improve their general health. However, more studies and trials need to be conducted to establish definite guidelines and recommendations regarding a dental examination prior to IVF.

\section{Acknowledgments}

We want to thank Drs Nada Afeiche and Nancy Abdo for their help during dental examination sessions. This work was supported by grants from the Medical Practice Plan at the American University of Beirut.

\section{Author contributions}

All authors contributed to data analysis, drafting or revising the article, gave final approval of the version to be published, and agree to be accountable for all aspects of the work.

\section{Disclosure}

The authors report no conflicts of interest in this work.

\section{References}

1. Eke PI, Dye BA, Wei L, Thornton-Evans GO, Genco RJ. Prevalence of periodontitis in adults in the United States: 2009 and 2010. J Dent Res. 2012;91(10):914-920. doi:10.1177/0022034512457373

2. Newnham JP, Newnham IA, Ball CM, et al. Treatment of periodontal disease during pregnancy: a randomized controlled trial. Obstet Gynecol. 2009;114(6):1239-1248. doi:10.1097/AOG.0b013e3181c $15 \mathrm{~b} 40$

3. Kinane DF. Causation and pathogenesis of periodontal disease. Periodontol 2000. 2001;25(1):8-20.

4. Williams RC, Barnett AH, Claffey N, et al. The potential impact of periodontal disease on general health: a consensus view. Curr Med Res Opin. 2008;24(6):1635-1643. doi:10.1185/03007990802131215

5. Ford PJ, Raphael SL, Cullinan MP, Jenkins AJ, West MJ, Seymour GJ. Why should a doctor be interested in oral disease? Expert Rev Cardiovasc Ther. 2010;8(10):1483-1493. doi:10.1586/erc.10.109
6. AlJehani YA. Risk factors of periodontal disease: review of the literature. Int J Dent. 2014. doi:10.1155/2014/182513

7. Champagne CM, Madianos PN, Lieff S, Murtha AP, Beck JD, Offenbacher S. Periodontal medicine: emerging concepts in pregnancy outcomes. J Int Acad Periodontol. 2000;2(1):9-13.

8. Gemmell E, Marshall RI, Seymour GJ. Cytokines and prostaglandins in immune homeostasis and tissue destruction in periodontal disease. Periodontol 2000. 1997;14(1):112-143.

9. Boggess KA, Beck JD, Murtha AP, Moss K, Offenbacher S. Maternal periodontal disease in early pregnancy and risk for a small-forgestational-age infant. Am $J$ Obstet Gynecol. 2006;194 (5):1316-1322. doi:10.1016/j.ajog.2005.11.059

10. Xiong X, Buekens P, Fraser WD, Beck J, Offenbacher S. Periodontal disease and adverse pregnancy outcomes: a systematic review. Int J Gynaecol Obstet. 2006;113(2):135-143. doi:10.1111/j.14710528.2005.00827.x

11. Hart R, Doherty DA, Pennell CE, Newnham IA, Newnham JP. Periodontal disease: a potential modifiable risk factor limiting conception. Hum Reprod. 2012;27(5):1332-1342. doi:10.1093/humrep/des034

12. Haytaç MC, Cetin T, Seydaoglu G. The effects of ovulation induction during infertility treatment on gingival inflammation. J Periodontol. 2004;75(6):805-810. doi:10.1902/jop.2004.75.6.805

13. Pavlatou A, Tsami A, Vlahos N, Mantzavinos T, Vrotsos I. The effect of in vitro fertilization on gingival inflammation according to women's periodontal status: clinical data. J Int Acad Periodontol. 2013;15(2):36-42.

14. Armitage GC. Development of a classification system for periodontal diseases and conditions. Ann Periodontol. 1999;4(1):1-6. doi:10.1902/annals.1999.4.1.1

15. Polyzos NP, Polyzos IP, Zavos A, et al. Obstetric outcomes after treatment of periodontal disease during pregnancy: systematic review and meta-analysis. Bmj. 2010;29(341):c7017. doi:10.1136/bmj.c7017

16. Offenbacher S, Jared HL, O'reilly PG, et al. Potential pathogenic mechanisms of periodontitis-associated pregnancy complications. Ann Periodontol. 1998;3(1):233-250. doi:10.1902/annals.1998.3.1.233

17. Neuer A, Spandorfer SD, Giraldo P, Dieterle S, Rosenwaks Z, Witkin SS. The role of heat shock proteins in reproduction. Hum Reprod Update. 2000;6(2):149-159.

18. Johnston-MacAnanny EB, Hartnett J, Engmann LL, Nulsen JC, Sanders MM, Benadiva CA. Chronic endometritis is a frequent finding in women with recurrent implantation failure after in vitro fertilization. Fertil Steril. 2010;93(2):437-441. doi:10.1016/j. fertnstert.2008.12.131

19. Cicinelli E, Matteo M, Tinelli R, et al. Chronic endometritis due to common bacteria is prevalent in women with recurrent miscarriage as confirmed by improved pregnancy outcome after antibiotic treatment. Reprod Sci. 2014;21(5):640-647. doi:10.1177/1933719113508817

20. Gibbs RS. The relationship between infections and adverse pregnancy outcomes: an overview. Ann Periodontol. 2001;6(1):153-163. doi:10.1902/annals.2001.6.1.153

21. Neuer A, Mele C, Liu HC, Rosenwaks Z, Witkin SS. Monoclonal antibodies to mammalian heat shock proteins impair mouse embryo development in vitro. Hum Reprod. 1998;13(4):987-990.

22. Pavlatou A, Dokou P, Tsami A. Periodontal disease, infertility treatment and in vitro fertilization (IVF). $J$ Fertil In Vitro IVF World Reprod Med Genet Stem Cell. 2015;3(2):148-154.

23. Segal S, Hill AV. Genetic susceptibility to infectious disease. Trends Microbiol. 2003;11(9):445-448.

24. Fujimoto VY, Luke B, Brown MB, et al. Society for assisted reproductive technology writing group. Racial and ethnic disparities in assisted reproductive technology outcomes in the United States. Fertil Steril. 2010;93(2):382-390. doi:10.1016/j.fertnstert.2008.10.061

25. Baker VL, Luke B, Brown MB, et al. Multivariate analysis of factors affecting probability of pregnancy and live birth with in vitro fertilization: an analysis of the society for assisted reproductive technology clinic outcomes reporting system. Fertil Steril. 2010;94 (4):1410-1416. doi:10.1016/j.fertnstert.2009.07.986 
26. Pussinen PJ, Paju S, Mantyla P, Sorsa T. Serum microbial-and host-derived markers of periodontal diseases: a review. Curr Med Chem. 2007;14(22):2402-2412.

27. Moreno I, Simon C. Relevance of assessing the uterine microbiota in infertility. Fertil Steril. 2018;110(3):337-343. doi:10.1016/j. fertnstert.2018.04.041

28. Simon C. Introduction: microbes in the female reproductive function, do they matter?. Fertil Steril. 2018;110(3):325-6.

29. Tilakaratne A, Soory M, Ranasinghe AW, Corea SM, Ekanayake SL, De Silva M. Effects of hormonal contraceptives on the periodontium, in a population of rural Sri-Lankan women. $J$ Clin Periodontol. 2000;27(10):753-757.

30. Parkar MH, Newman HN, Olsen I. Polymerase chain reaction analysis of oestrogen and androgen receptor expression in human gingival and periodontal tissue. Arch Oral Biol. 1996;41(10):979-983.

31. Khan KN, Fujishita A, Masumoto H, et al. Molecular detection of intrauterine microbial colonization in women with endometriosis. Eur J Obstet Gynecol and Reprod Biol. 2016;1(199):69-75. doi:10.1016/ j.ejogrb.2016.01.040
32. Kavoussi SK, West BT, Taylor GW, Lebovic DI. Periodontal disease and endometriosis: analysis of the national health and nutrition examination survey. Fertil Steril. 2009;91(2):335-342. doi:10.1016/ j.fertnstert.2007.12.075

33. Vasudevan S, Renuka JV, Sylvia DS, Challa R, Padmakanth M, Reddy A. Evaluation of gingival inflammation in patients using ovulation induction drugs before and after scaling. J Contemp Dent Pract. 2013;14(6):1165. doi:10.5005/jp-journals-100241469

34. Moreno I, Codoñer FM, Vilella F, et al. Evidence that the endometrial microbiota has an effect on implantation success or failure. Am J Obstet Gynecol. 2016;215(6):684-703. doi:10.1016/j.ajog.2016.09.075

35. Wee BA, Thomas M, Sweeney EL, et al. A retrospective pilot study to determine whether the reproductive tract microbiota differs between women with a history of infertility and fertile women. Aust N Z J Obstet Gynaecol. 2018;58(3):341-348. doi:10.1111/ajo.12754

\section{Publish your work in this journal}

The International Journal of Women's Health is an international, peerreviewed open-access journal publishing original research, reports, editorials, reviews and commentaries on all aspects of women's healthcare including gynecology, obstetrics, and breast cancer. The manuscript management system is completely online and includes a very quick and fair peer-review system, which is all easy to use. Visit http://www.dovepress.com/testimonials.php to read real quotes from published authors. 